\title{
KONSTRUKCIJA ZNANJA I INTERAKCIJA NA UNIVERZITETSKIM PREDAVANJIMA DIGITALNOG DOBA ${ }^{1}$
}

\begin{abstract}
APSTRAKT: Predavanja su obavezni deo univerzitetskog obrazovanja u Srbiji. Propisuje se, čak, 50 do $60 \%$ predavanja u odnosu na druge oblike nastave kao što su vežbe i seminari. $\mathrm{Na}$ taj način se stiče utisak da se predavanjima pridaje veliki značaj, iako se ona već odavno smatraju zastarelim i neefikasnim vidom nastave, budući da im je uglavnom svrha samo prenošenje znanja, bez aktiviranja viših kognitivnih sposobnosti kod studenata ${ }^{2}$. Kritika uglavnom stiže iz pravca konstruktivizma i komunikativne didaktike, što predstavlja podsticaj za reviziju ovog oblika nastave, kao i za primenu digitalnih medija u cilju inovacije i modernizacije univerzitetskih predavanja. Cilj ovog rada je da se izlože odlike predavanja, njihova kritika i predlozi prevazilaženja njihovih slabosti korišćenjem digitalnih medija koji pružaju mogućnost za samostalnu konstrukciju znanja i interakciju studenata s nastavnim materijalima.
\end{abstract}

Ključne reči: digitalni mediji, instruktivizam, interakcija, konstruktivizam, predavanja, univerzitetska nastava.

\section{KNOWLEDGE CONSTRUCTION AND INTERACTION AT UNIVERSITY LECTURES OF DIGITAL AGE}

ABSTRACT: Lectures are an obligatory part of university education in Serbia and it is even proscribed that they have to amount to 50 to $60 \%$ of all teaching classes in comparison to seminars and exercises. This gives an impression that lectures have been ascribed great relevance, although they have already been considered an outdated and inefficient teaching form for long time, because their purpose is only knowledge transfer without the activation of higher cognitive skills in students. Criticism has mostly been directed by the representatives of constructivist and communicative didactics and has provided an incentive for the revision of this teaching form, as well as for the application of digital media for the purpose of innovation and modernization of university lectures. The aim of this paper is to describe the features of lectures, to offer criticism and suggestions for amending their

\footnotetext{
${ }^{1}$ Rad je rezultat projekta Jezici i kulture u vremenu i prostoru (br. 178002) koji finansira Ministarstvo prosvete, nauke i tehnološkog razvoja Republike Srbije.

${ }^{2}$ Svi pojmovi u ovom radu koji su upotrebljeni u muškom gramatičkom rodu obuhvataju muški i ženski rod lica na koja se odnose.
} 
weaknesses with the support of digital media that provide students with opportunities for an autonomous construction of knowledge and interaction with teaching materials.

Key words: lectures, instructivism, university teaching, constructivism, interaction, digital media.

\section{UNIVERZITETSKA PREDAVANJA - TRADICIJA I INOVACIJA}

Nastava na univerzitetima se uglavnom realizuje u vidu predavanja i praktične nastave (vežbe, seminari i sl.), pri čemu propisi za akreditaciju (Standardi za akreditaciju studijskih programa prvog i drugog nivoa visokog obrazovanja 2017: 164) dobijanje dozvole za rad uslovljavaju sa 50 do $60 \%$ predavanja na prvom nivou studija u odnosu na praktične oblike nastave, čime se predavanjima pridaje veliki značaj u okviru univerzitetskog obrazovanja, što nije sasvim u skladu sa zahtevima savremene nastave, naročito kada je reč o tradicionalnom konceptu predavanja.

\subsection{Pojam i odlike predavanja}

Univerzitetska predavanja u svojoj osnovnoj definiciji predstavljaju kompleksnu aktivnost nastavnika u nastavnom procesu i obuhvataju prezentaciju nastavnih sadržaja, objašnjavanje, podsticanje, kontrolu, pružanje podrške učenicima $^{3}$ u savladavanju gradiva, njihovo obrazovanje i vaspitavanje (Raičević 2011: 146). Tipični tradicionalni modeli predavanja su: čitanje naglas, izlaganje na osnovu pripremljenih teza, izlaganje teorijskih sadržaja, predavanje sa zabavnim načinom izlaganja i predavanje ilustrovano mnoštvom slika iz stvarnosti (Bogičević 2009: 44). Pošto je predavanje vezano za obradu nastavnih sadržaja, dominiraju verbalne metode, a suštinu predavanja čini nekoliko manifestnih aktivnosti predavača (izlaganje, ekspliciranje, interpretacija) (Bogičević 2009: 45). Preovlađuje frontalni, odnosno kolektivni oblik rada, nastavnik je u direktnom odnosu s učenicima i nastavnim sadržajem, odnosno posreduje između nastavnog sadržaja i učenika dok oni istovremeno rade na tom nastavnom sadržaju (Požar 2017: 338). Prednosti frontalnog rada su ekonomičnost i jednostavnost, osećanje zajedništva i jednakosti, istovremeno započinjanje i završavanje zadataka, uz mogućnost posmatranja svih učenika. Nezamenljiv je pri davanju uputstava i

\footnotetext{
${ }^{3}$ U relevantnoj literaturi uglavnom se govori o školskom okruženju i učenicima, ali sva ova razmatranja se mogu preneti i na studente, i na njih se u ovom radu prevashodno i odnose.
} 
pojašnjenja, a njime se slabiji učenici podstiču na intenzivniji tempo (Požar 2017: 339).

Nedostatak frontalnog načina rada na predavanjima jeste zapostavljanje studenata (oni samo slušaju i odgovaraju), a učenje se generalno prilagođava „prosečnim studentima”, a bolji i slabiji se prisiljavaju na isti tempo rada, dok se većina pasivizira. Javlja se i problem ,psihologije gotovanstva”, a nastavnik se brzo umara i nema uvida u aktivnosti učenika (Požar 2017: 339). Iz tog razloga se i tradicionalno predavanje često posmatra kao autokratski oblik poučavanja koji sprečava stvarno učenje i samostalnu konstrukciju znanja (Apel 2003: 9), jer slušaoci neprestano filtriraju i jure za izgovorenom rečju predavača koji nastavljaju da govore ne mareći za duhovne mogućnosti slušalaca preplavljenih mnoštvom informacija. Tradicionalna predavanja predstavljaju receptivnu situaciju poučavanja i učenja, a često se smatra i besmislenim izlaganje gradiva koje je već zapisano, pogotovo bez samostalnog sučeljavanja s izloženim (Apel 2003: 28). Takva predavanja predstavljaju ostatke dogmatsko-reproduktivnog i reproduktivno-eksplikatornog metodičkog sistema koji se smatraju prevaziđenim, budući da se zasnivaju na reprodukciji ,gotovih” znanja (Petrovački, Štasni 2010: 21). Kao osnovna slabost tradicionalne nastave ističe se nedovoljna aktivnost učenika, odnosno siromašna interakcija (Vilotijević 2016: 111), jer je aktivnost nastavnika uglavnom veća od učeničke (Vilotijević 2016: 115), što u aktivnoj školi ne bi trebalo da bude slučaj. Stoga, predavanja treba da se modernizuju kako bi išla u korak sa savremenim tendencijama u obrazovanju.

\subsection{Aktivnost učenika i studenata}

Didaktičko-metodički principi savremene nastave podrazumevaju usmerenost na kompetencije (Kompetenzorientierung), interakciju (Interaktionsorientierung), delanje (Handlungsorientierung) i na učenike (Lernerorientierung), njihovo aktiviranje (Lerneraktivierung), podsticanje njihovog autonomnog učenja (Förderung von autonomem Lernen), kao i interkulturnu orijentaciju (interkulturelle Orientierung) (Ende, Grotjahn, Kleppin, Mohr 2013: 114-115). Svi navedeni principi objedinjeni su u konceptu aktivnog učenja.

Aktivno učenje predstavlja otvoren sistem za upliv raznih savremenih obrazovnih inovacija i tretira nastavni proces kao dinamički, interaktivni tok u stalnom razvoju. Zahtev koji pretpostavlja aktivnog učenika u nastavnom procesu ističe se već vekovima i podrazumeva spontane aktivnosti deteta koje su inicirane njegovim interesovanjima i samostalnim istraživačkim akcijama. Za razliku od 
nastave koja je usmerena na program i rezultuje školskim verbalizmom, neprilagođenošću programa mogućnostima i interesovanjima dece, njihov pasivan položaj dok postaju recipijenti bez prava glasa, škola usmerena na decu ima kao rezultat nesistematičnost i neujednačenost obrazovanja. Usvajanju sistematizovanih akademskih, školskih znanja (uzoraka kulture) suprotstavlja se učenje kroz delanje (learning by doing). Aktivno učenje podrazumeva Pijažeovu aktivnu konstrukciju znanja i zajedničke aktivnosti, odnosno ko-konstrukciju znanja deteta i odraslog L. Vigotskog u okviru asimetrične interakcije u školi. Aktivnosti predstavljaju vrste mentalnog procesa izazvanih učenjem i nerazdvojno su povezane sa prirodom sadržaja tih aktivnosti, odnosno zavise od prirode i tipa znanja, jer svakoj naučnoj disciplini odgovara drugi metodološki arsenal. Škola bi trebalo da bude mesto intenzivne integracije spontanih i naučnih pojmova, jer cilj nije samo usvajanje školskog programa, već i razvoj ličnosti i individualnosti svakog deteta kroz proširenje repertoara metoda. Pri tome mora se voditi računa o motivaciji za učenje, osposobljavanju i osamostaljivanju u učenju, otvaranju prostora za bogati repertoar dečjih aktivnosti (vođenje argumentovanog dijaloga, javna prezentacija vlastite ideje, saradnja s drugima na istom problemu, pravljenje izbora, kreiranje novog rešenja). Iako je svako učenje suštinski aktivno, stepeni aktivnosti i mentalnih procesa angažovanih u raznim oblicima učenja se razlikuju. Aktivne metode su one koje zahtevaju složenije i više mentalne procese, kreativnost, povezivanje znanja, samostalnost, inicijativu, slobodu izbora i izražavanja učenika (Ivić, Pešikan, Antić 2001: 192-195). Aktivna škola fokusirana je na učenika kao kompletnu ličnost (Požar 2017: 342), ne postoji fiksni, celoviti plan i program, učenje se nadovezuje na prethodno znanje i lično životno iskustvo, motivacija je unutrašnja, cilj je razvoj ličnosti i individualnosti, ne samo usvajanje programa, a na kraju se ocenjuje zadovoljstvo učenika naučenim, njegov napredak, motivisanost i zainteresovanost za rad i aktivnost. Praktično je moguće napustiti neke karakteristike tradicionalne škole kao što su predavanja kao jedini vid nastave, pasivnost učenika, ocenjivanje samo reprodukcije znanja, uvažavanje deteta u školi, uzimanje u obzir njegovih uzrasnih i individualnih karakteristika, proširivanje reportoara nastavnih metoda pri realizaciji unapred utvrđenih programa, vođenje računa o motivaciji učenika za učenje, podsticanje razvoja kao jednog od ciljeva, a ne samo usvajanje gradiva (Požar 2017: 343). Tradicionalna škola ima definisan plan i program na osnovu kojeg se vrši verbalno prenošenje znanja, a uloga učenika je da savlada obavezno gradivo i da ga s razumevanjem ponovi, motivacija mu je spoljašnja (Požar 2017: 342). Kao i tradicionalna škola i tradicionalni univerzitet ima iste odlike, pri čemu to najviše dolazi do izražaja upravo na predavanjima. 


\subsection{Predavanja i mišljenje}

Apel smatra da predavanja kao oblik univerzitetske nastave treba da prikažu temeljna pitanja naučne discipline i da predstavljaju niz sadržajno povezanih izlaganja, s namerom da se prenesu naučne spoznaje i metode istraživanja, ali i da se kod studenata razvije problemska svest i kritičko mišljenje, interesovanje i celovito znanje (Apel 2003: 12). Smisao predavanja stoga ne bi trebalo da bude samo slušanje, već i misaono angažovanje (Bogičević 2009: 45), ona bi trebalo da podstaknu na razmišljanje, proširenje znanja, problematizovanje postojećih mišljenja, otvaranje perspektiva (Apel 2003: 13). Da bi se to postiglo, predavanja moraju da se didaktički i retorički oblikuju, da se primene na situaciju u učionici, da se ožive (Apel 2003: 11) razgovorom, dijaloškim oblicima poučavanja i snažnijim učešćem studenata (Apel 2003: 25). Zato je važno da se tokom predavanja podstiče razmišljanje studenata $i$ da se mogu postaviti pitanja (Apel 2003: 29), čak i da se studenti izazovu na suprotstavljanje i sučeljavanje mišljenja (Apel 2003: 32). Radi prevazilaženja nedostataka frontalnog oblika nastave treba koristiti frontalno-interaktivni pristup, tako da nastavna jedinica bude obrađena kao sistem problemskih pitanja i da omogućava učenicima da budu aktivni učesnici, da samostalno uče nove sadržaje, da ih vežbaju, ponavljaju, da povezuju teoriju s praksom. Samo kad rade samostalno oni su u direktnom odnosu s nastavnim sadržajima, bilo da rade u grupi, individualno ili u paru (Požar 2017: 339), što uglavnom nije slučaj na tradicionalnim predavanjima.

Predavanja se tradicionalno usmeravaju na znanje i razumevanje, odnosno na niže kognitivne ciljeve, dok se viši ciljevi primene, analize, sinteze i evaluacije ${ }^{4}$ uglavnom zapostavljaju. Čak se i kod sticanja znanja nastava često zadržava na najnižem nivou rekognicije i memorisanja, i gubi se iz vida da znanja predstavljaju sistem ili logički pregled ne samo činjenica, već i generalizacija o objektivnoj stvarnosti koje je čovek usvojio i trajno zadržao u svojoj svesti. Dakle, da bi znanje bilo potpuno, osim poznavanja činjenica ono mora da obuhvata i poznavanje

\footnotetext{
4 Postoje različite taksonomije obrazovnih ciljeva, pri čemu je najpoznatija Blumova iz 1956. godine koja obuhvata znanje, razumevanje, primenu, analizu, sintezu i evaluaciju. Anderson i Kratvol su Blumovu taksonomiju preradili 2001. godine, tako da novi model obuhvata pamćenje, shvatanje, primenjivanje, analiziranje, evaluaciju i stvaranje. Marzan i Kendel (2006) navode rekogniciju, razumevanje, analizu, upotrebu znanja, metakogniciju i samosistemsko mišljenje, dok su ciljevi nastave prema PISA (2000) pristup znanju, upravljanje znanjem, njegova integracija, evaluacija, konstrukcija i komunikacija (Fadel, Bialik, Trilling 2015: 117). U ovom radu će se koristiti kombinacija izvorne i revidirane Blumove taksonomije.
} 
generalizacija i apstrakcija, a to su pojmovi, pravila, principi, metode, zakoni, norme, postavke, hipoteze, teorije, misli, ideje, sistemi, simboli, termini, formulacije, vrednosti, itd. Generalizacije se mogu shvatiti posredstvom mišljenja na osnovu percipiranih činjenica i razmišljanja o njima. U nastavnom procesu tokom sticanja znanja nastaju pogreške upravo usled narušavanja nužnog odnosa između činjenica i generalizacija i načina njihove spoznaje. Pogreške najčešće nastaju kada se na predavanjima prezentuju samo činjenice, a ne ide se dalje, prema uopštavanju i relevantnom zaključivanju, odnosno ka shvatanju generalizacije, ili se pak generalizacije izlažu samo verbalno, bez činjeničnih podataka koji predstavljaju njihovu materijalnu supstancu. S obzirom na usvojene činjenice i generalizacije, iskazuju se različite dimenzije znanja, kao što su fond, kvalitet, kvantitet, funkcionalnost i primenljivost znanja (Raičević 2011: 53).

U skladu s time razlikujemo pet pojmova učenja: 1) učenje kao sticanje činjeničkog znanja, 2) memorisanje, 3) znanje usmereno na primenu, 4) učenje kao proces saznanja i 5) učenje kao subjektivni proces interpretacije koji se nadovezuje na iskustvo. Prvo učenje spada u procese učenja koji predstavljaju površni pristup učenju (memorisanje i reprodukcija), dok ostali predstavljaju više forme učenja i važe za duboki pristup učenju. $U$ tome se krije implicitno poređenje $\mathrm{s}$ biheviorističkim i konstruktivističkim teorijama učenja (Tenberg 2003: 214). Predavanja se tradicionalno zasnivaju na biheviorizmu i instruktivizmu, koji su meta kritike savremenijih konstruktivističkih teorija, što samim tim podrazumeva i kritiku ovog oblika nastave.

\section{KONSTRUKTIVIZAM I KRITIKA PREDAVANJA}

Bihevioristički pristup zasniva se na formiranju navika putem višestrukog mehaničkog ponavljanja (Raičević 2011: 19-20). Instruktivizam je zasnovan na biheviorizmu i predstavlja direktni transfer struktura znanja koje se prezentuje kao objektivno dato, kao zaokružena celina, često bez konteksta. Instrukcija je usmerena na rezultat, implicira utvrđivanje detaljnih nastavnih ciljeva, progresivno uređenog deklarativnog znanja, konkretnih zadataka i eksternu evaluaciju. Nastavnik je uglavnom aktivan i dominantan, njegov rad se zasniva na udžbeniku i nastavnom materijalu, on prezentuje probleme i inicira načine za njihovo rešavanje. Instrukcije mogu biti usmerene na sadržaj ili formu, direktne, adaptivne, uz primenu računara, uzajamne instrukcije i autonomno učenje. Prednosti direktnih instrukcija su vremenska, sadržinska i organizaciona preglednost, pouzdanost i proverljivost građe, a glavni nedostatak je nizak motivacioni faktor i podrška usvajanju tromog, retko transferbilnog znanja. Budući da je zasnovan na 
premisama biheviorizma, instruktivizam se često posmatra kao neprijatelj konstruktivizma, ali početkom novog veka se teži kompromisima između instruktivizma i (umerenog) konstruktivizma (Badstübner-Kizik 2010: 115). Instruktivističke i konstruktivističke zadatke treba objediniti u zajednički koncept (Blei 2003: 226), kako bi se spojile prednosti oba pristupa i prevazišli njihovi nedostaci.

Suština konstruktivističke teorije ogleda se u shvatanju da svaki pojedinac spoznajom konstruiše predmet koji posmatra, što znači da znanje postoji samo u glavama ljudi, pri čemu se naglašava uloga društvenog i kulturnog elementa $u$ učenju. Konstruktivizam kao teorija učenja polazi od nekoliko premisa: kognitivne aktivnosti nisu usmerene ka saznavanju objektivne stvarnosti, već ka stvaranju subjektivnog iskustvenog sveta, što znači da se znanje ne prima pasivno, već pojedinac svojim kognitivnim aktivnostima oblikuje svoje znanje, u individualnom procesu. Najefikasnije je ako pojedinac sam upravlja tim procesom i preuzima odgovornost za njega, a nastavnik mu samo pruža podršku, a ne i gotova znanja (Durbaba 2011: 69-70). Konstrukcija predstavlja osnovu svih kognitivnih procesa, ona je nužan, trenutačan, autonoman i kreativan proces obrade informacija, jer u interakciji između već postojećeg znanja i novih informacija nastaje nova struktura znanja, odnosno subjektivni konstrukti znanja. Tek tada počinje učenje, jer učenje jeste konstrukcija (Blei 2003: 221). Prilikom konstrukcije razlikujemo procese koji se odnose na pripremu interakcije između postojećeg znanja i novih informacija, procese koji oblikuju interakciju i procese koji omogućavaju integraciju konstruisanog znanja u pamćenje (Blei 2003: 222). Navedenim procesima bavi se konstruktivistička didaktika.

Konstruktivistička didaktika preuzima jedan deo nastavnih koncepata usmerenih na interakciju iz komunikativne didaktike ${ }^{5}$ i nastavnih koncepata usmerenih na iskustvo i delanje (aktivnost). Konstruktivističko mišljenje se može pripisati post-klasičnom, postmodernom razumevanju nauke, jer je znanje konstrukcija, znanje po sebi nije privilegovano, a učenje je čin (ko)-konstrukcije u zajednici. Za konstruktivističku didaktiku je karakterističan trokorak: 1) konstruisanja (učenik u socijalnom kontekstu za sebe kreira svoju stvarnost), 2) rekonstruisanja (nije sve novo, tako da se stvarnost ne samo kreira, već i otkriva) i

\footnotetext{
${ }^{5}$ Procesi i delovanje socijalne interakcije u učionici su predmet komunikativne didaktike koja se manje koncentriše na sadržaj i perspektivu nastavnika koji planira i analizira nastavu. Nastava se posmatra kao socijalna situacija u koju učesnici donose i iznose svoja lična iskustva, viđenja i definicije. Komunikativna didaktika se usmerava na cilj ostvarivanja simetrične komunikacije u učionici (Terhart 2009: 140-142).
} 
3) dekonstruisanja (kritički se proveraju sopstvena kreacija i otkrića). Konstruktivističke preporuke za oblikovanje nastave bliske su starim i novim modelima reformske pedagogije (učenje iz iskustva, otkrivajuće učenje, integrativna nastava, podsticanje samodelatnosti, učenje učenja) i preklapaju se s novim, umreženim kulturama učenja, novim konceptima neformalnog učenja i elektronskog učenja (Terhart 2009: 144-146). To znači da nastavnici gube preglednost i kontrolu nad nastavnim procesom, kao i da učenici i studenti preuzimaju veću odgovornost i za proces i za ishode učenja, što podrazumeva određenu zrelost i samokritičnost koje se ne mogu uvek očekivati. Iz tog razloga je i smisleno kombinovati instruktivizam i konstruktivizam.

Zastupnici konstruktivističkih modela kritikuju tradicionalni vid predavanja kao neefektivan jer ne pospešuje aktivno usvajanje znanja. Kritika predavanja dolazi i od zagovornika multimedijalnih oblika prezentovanja sadržaja koji smatraju da je poučno izlaganje zastarelo jer se u njemu ne koriste mogućnosti samodeterminisanog učenja s više čula i samoodabranim putevima. Sredstva multimedijalne prezentacije otvaraju nove kvalitete poučavanja i učenja preko interaktivnih oblika poučavanja, učenja i komunikacije (Apel 2003: 26). Kritike poput ovih dovele su do nastanka predavanja koja se povezuju sa časovima vežbi i diskusijama (lecture-course), raspravnog (diskusijskog) predavanja (u obliku katedarskog razgovora između različitih naučnika) i interaktivnog predavanja (Apel 2003: 13). Za razliku od klasičnog predavanja kod kojeg dominira jezično prenošenje povezano s dobrom didaktičkom organizacijom, kod interaktivnog predavanja se izmenjuju izlaganje znanja s njegovim tumačenjem (Apel 2003: 65). Multimedijski programi učenja dopuštaju slobodan izbor radnog vremena, nude interaktivno učenje s trenutnom povratnom informacijom o tome da li je neki zadatak rešen tačno ili netačno i zahtevaju samostalnu delatnost studenata (Apel 2003: 101). Iz tog razloga se mediji sve više povezuju s konceptom interakcije u teoriji i praksi.

\section{INTERAKCIJA U NASTAVI}

U najširem smislu interakcija predstavlja međusobni uticaj ljudi, prirodnih pojava i dr. U opštoj i razvojnoj psihologiji odnosi se na uzajamno dejstvo i uticaj nekih činilaca (naslednih, socijalnih, personalnih $\mathrm{i}$ dr.) u oblikovanju jedinke (Raičević 2011: 63). Kod uzajamnog ponašanja dveju ili više jedinki jedan postupak pobuđuje recipročno ili nesrazmerno drugi, sa mogućim daljim međuticajem. Interakcija može biti društvena ili senzorna. Društvena se odnosi na međusobni dinamički odnos u društvenom prostoru, dok se senzorna odnosi na 
uzajamno dejstvo jednovremeno datih različitih podatka u okviru posebnih čulnih modaliteta, $u$ šta spada i međusobno uticanje i mešanje procesa u različitim čulima (Vilotijević 2016: 115). U nastavi se razlikuju sledeći interaktivni odnosi: nastavnik - učenik, nastavnik - mogućnosti učenja (oblici rada, materijali, mediji, zadaci), učenici - mogućnosti učenja, učenici - učenici (Funk, Kuhn, Skiba, Spaniel-Weise, Wicke 2014: 48). Bitno je da učenici imaju priliku da utiču na nastavni proces, njegov sadržaj, strukturu, a posebno tempo.

Cilj interaktivnog modela jeste da se akcija prenese $s$ nastavnika na učenike, da oni uče zajednički, da primenjuju naučeno i da vrednuju proces, što utiče na motivaciju, razvijanje saradnje, tolerancije, moderne komunikacije i upotrebu različitih medija i izvora znanja. Učenici preuzimaju inicijativu, otkrivaju obrasce i značenja (apstrakcija), uočavaju odnose među pojavama, kritički misle i rešavaju probleme, razvijaju socijalne kompetencije. Timski oblik rada (interaktivna, saradnička ili kooperativna nastava) je socijalna formacija koja podrazumeva zajedničko planiranje i ostvarivanje plana, ali i nalaženje sopstvenog puta u trajnom učenju. Dolazi do razmene ideja i znanja, učenje je podeljeno, ali učenici su sami odgovorni za svoje učenje (Požar 2017: 344-345). Prednosti kooperativno-interaktivnog učenja su bolji uspeh i produženo pamćenje, češće razmišljanje višeg reda, dublje razumevanje i kritičko mišljenje, usmereniji rad i manje nediscipline, veća motivisanost za bolje ocene i učenje, veća sposobnost da se situacija razmotri iz tuđe perspektive, pozitivniji, tolerantniji i prijateljski odnos sa vršnjacima, veće društveno podržavanje, bolje prilagođavanje, pozitivniji odnos prema samom sebi, veće društvene kompetencije, pozitivniji stavovi prema nastavnim predmetima, učenju i školi, pozitivniji odnos prema nastavnicima (Požar 2017: 347). Interakcija se ostvaruje uz pomoć odgovarajućih metoda (dijaloškoverbalna), oblika rada (rad u tandemu i u grupi) i medija (digitalni mediji).

Forme interakcije se realizuju putem diskusije koja podstiče kognitivne sposobnosti, aktivno ponavljanje informacija, odbranu ideja i argumenata, razmene (suprotstavljanje) mišljenja, ideja, informacija u kooperativnim grupama, aktivnih razgovora prilikom rešavanja zadataka. Ishodi treba da budu stvaralačka primena znanja u životu i praktičnom iskustvu; kompetencije i znanja za život; sposobnost snalaženja, pronalaženja, istraživanja; odgovornost, radoznalost, sumnja; tolerancija, razumevanje drugih; timski rad (Požar 2017: 350-351). Iako interakcija predstavlja sve komunikativne procese u nastavi, pre svega kooperativni oblici rada vode ka aktivnom učešću učenika (Funke et al. 2014: 49), stoga se interakcija često i izjednačava s radom u tandemu i u grupi.

Kooperativni rad doprinosi trajnijem usvajanju znanja, povećanju misaone aktivnosti i samostalnosti učenika, razvijanju kritičkog i kreativnog mišljenja, 
komunikacijske i socijalne veštine, podsticanju razmene iskustava i zajedničkom rešavanju problema, kako bi se pojedinačni ciljevi povezali sa zajedničkim (Požar 2017: 337). Samo aktivnim radom učenika može se obezbediti efikasno učenje, a za efikasnu interakciju je bitno da se pravilno formiraju male grupe, da se podrži individualna uključenost, razvijaju interpersonalne i kognitivne sposobnosti, stvara povoljna emocionalna klima, analiziraju i vrednuju rad i efekti grupnog rada, odaberu adekvatne metode interaktivnog učenja (Đorđević 2007: 90). Kod grupnog rada je pritom važno da se zadrži jasna struktura i preglednost, što se postiže odgovarajućom organizacijom časa.

Grupni rad treba da prođe kroz određene etape: 1) uvodni deo - dogovor o radu - zajednički je za sve učenike, sprovodi se sadržajna i psihološka priprema, kao i upoznavanje s programom rada, formiraju se grupe, zadaju zadaci i pripremaju izvori znanja; 2) glavni deo rada - rad u grupi - samostalni rad u grupi praćen je podelom rada unutar same grupe, uz dogovore, prikupljanje podataka, beleške, diskusiju i pripreme izveštaja; 3) završni deo - uopštavanje - obuhvata izveštaje grupe, diskusiju i nastavnikovo uopštavanje (dodatna tumačenja, dopunjavanje izveštaja, zadavanje dodatnih zadataka i slično), praćeno proverom efikasnosti nastavnog rada (Požar 2017: 340). Prednosti grupnog rada su neposredan odnos učenika sa izvorima znanja i sa ostalim učenicima u grupi, što razvija komunikativne sposobnosti i sposobnost za timski rad i saradnju. Učenici se uče pravilnom izražavanju, pažljivom slušanju, radu na zajedničkom cilju. Rad je dinamičan, zanimljiv, doprinosi intelektualnom razvoju i provocira kritičnost i razvija samostalnost. Nedostatak je složenost formiranja grupe, trošenje vremena na uvodni deo, problemi s disciplinom i dominacijom pojedinaca, gubitak kontrole nad uspehom pojedinih učenika (Požar 2017: 341). Iz tog razloga i treba uspostaviti ravnotežu između vođenog učenja usmerenog na nastavne ciljeve i autonomnog, otkrivajućeg, nelinearnog učenja (Tenberg 2003: 216).

Pod interakcijom se može podrazumevati i čitaočevo bavljenje nekim tekstom ili obrada nekog zadatka. $\mathrm{U}$ to spada i rad sa interaktivnim medijima poput digitalne table (Funke et al. 2014: 49). Nastava može postati interaktivna i uz primenu obrazovnih tehnologija, odnosno uz pomoć multimedija, virtuelnog predavanja i konzervisanog predavanja (Bogičević 2009: 42-43). Bitno je samo da se ove tehnologije primene na pravi način i da daju povod za interakciju, a ne za instruktivizam.

Bez obzira na to o kojim se medijima radi, učenike treba podstaći na aktivno učešće, što podrazumeva da se radi o pravoj, recipročnoj dijaloškoj strukturi u kojoj oba partnera interakcije imaju šanse za intervenciju, da je materijal dostupan iz različitih perspektiva, da učenik ima mogućnost za učešće u grupnoj 
diskusiji koja može biti i sinhrona i dijahrona, da se učenici i nastavnici zajedno dogovaraju u vezi sa temama za pojedinačne i/ ili grupne projekte koji su usmereni prema interesovanju i specifičnim znanjima učenika, da se nadovezuju na predznanja učenika, da su učenici podstaknuti na pravljenje kognitivnih struktura (mapa uma) i sistemskih odnosa između predznanja i novog znanja, da je učeniku dat metodički instrumentarijum s kojim preispituje sopstveno predznanje i transformiše ga novim saznanjima (Tenberg 2003: 215).

\section{DIGITALNI MEDIJI I INTERAKTIVNOST}

U učenju u digitalnom dobu dolazi do smene generacija (Davidson, Goldberg 2012: 250). Današnja deca (a uskoro i studenti) jesu „digitalni urođenici”, budući da su rođeni i žive u digitalnom dobu. Današnji nastavnici su odrasli pre digitalnog doba i zauzimaju ili poziciju „digitalnih izbeglica” ili „digitalnih pridošlica”. Digitalne izbeglice će radije bežati nego se integrisati u digitalnu kulturu, jer se osećaju izgubljeno u zastrašujućem i opasnom okruženju, osećaju se kao beskućnici, motivisani su strahom, imaju želju da izbegnu promenu i aktivno joj se suprotstavljaju. Nastavnici koji prihvataju ulogu digitalnih pridošlica spremni su da se prilagode novom dobu, svesni su da se njihova uloga promenila i da moraju da se usavršavaju, da digitalnim urođenicima pokažu da se tehnologija može koristiti i za učenje, ne samo za igru i zabavu. Zato je potrebno da dobro osmisle nastavne situacije u kojima će učenici aktivno učestvovati $u$ izgradnji sopstvenog znanja kroz istraživački rad, rešavanje problema, saradnju i komunikaciju sa drugim učenicima, vršnjačko učenje, samostalno ili timsko kreiranje nastavnih materijala, analiziranje i vrednovanje izvora informacija i sopstvenog rada, sa akcentom na bezbednost na internetu i stvaranje ispravnog medijskog identiteta. Nastavnik treba da proceni digitalne alate i odabere onaj koji najviše odgovara postavljenom ciju i omogućava učenicima da ispolje svoje potencijale, da uče i van učionice, da aktivno učestvuju u izgradnji znanja, da individualno transformišu prikupljene informacije u znanje, kao i da preuzmu odgovornost prema sopstvenom učenju (Čakarević 2014: 207-211). Da bi ih postakli na to, nastavnici moraju i sami da vladaju odgovarajućim znanjima i veštinama.

Za pripremu nastavnih materijala potrebne su kompetencije uređivanja, vrednovanja, obrade i evaluacije internet-izvora, kao i tehničke veštine rada $\mathrm{s}$ pretraživačima i različitim programima (Tenberg 2003: 218). Danas se te kompetencije nazivaju digitalnim kompetencijama i spadaju u ključne (opšte) kompetencije kojima bi trebalo da raspolaže svaki nastavnik. 
Digitalne kompetencije predstavljaju skup znanja, veština, stavova, sposobnosti i strategija neophodnih za kvalitetno korišćenje informacionokomunikacionih tehnologija (IKT) i digitalnih medija sa ciljem promišljenog, fleksibilnog i bezbednog unapređivanja procesa nastave i učenja i drugih aktivnosti u vezi s nastavničkom profesijom u onlajn i oflajn okruženju. Digitalna tehnologija je važna jer nastavnici prate napredak učenika i dobijaju više detalja o njihovim trenutnim veštinama, nastavnici uobličavaju nastavna sredstva i pomagala, a učenici uče brzinom koja im odgovara. Digitalne kompetencije se dele na tri nivoa kompetentnosti (početni, srednji i napredni) i na osam kategorija: 1. pretraga, pristup, čuvanje i upravljanje informacijama, 2. pretraga, adaptacija i kreiranje digitalnih sadržaja za nastavu i učenje, 3. upravljanje digitalnim sadržajima za nastavu i učenje i njegovo deljenje, 4. upravljanje okruženjem za učenje, 5. nastava i učenje, 6. formativno i sumativno ocenjivanje, beleženje, praćenje i izveštavanje o napretku učenika, 7. komunikacija i saradnja u onlajn okruženju i 8. etika i bezbednost (Okvir digitalnih kompetencija 2017: 5-7). Budući da se digitalni mediji menjaju velikom brzinom, smenjuju se generacije nastavnika s različitim odnosom prema digitalnoj kulturi i stalno dolazi do pomeranja nivoa digitalne kompetentnosti.

Digitalni mediji sami po sebi nisu ni interaktivni, niti nužno predstavljaju sredstvo za konstrukciju znanja. Mogu da se stave u službu biheviorizma i instruktivizma i da posluže kao sredstvo konstrukcije znanja i interakcije - u zavisnosti od načina njihove implementacije, odnosno od didaktičko-metodičkih kompetencija nastavnika. Mnogi nastavnici smatraju da je primena ppt prezentacija (Powerpoint) veliki pomak u nastavi i njenoj modernizaciji, ali se na taj način samo menja sredstvo, ali ne i suština, jer nastava i dalje ostaje frontalna i verbalna. Primena vizuelnih elemenata nije preduslov za interaktivnu nastavu, ali može da predstavlja podsticaj.

Kao teorijska osnova nastave i učenja uz pomoć kompjutera uzimaju se teorija deskriptivnog biheviorizma, odnosno Skinerova varijanta biheviorizma koja zanemaruje funkciju mišljenja $\mathrm{i}$ ističe da je najbitnije ispoljavanje elementarnih reakcija kao odgovora na date stimulanse, pri čemu Skiner funkciju svodi na prilagođavanje. Učenje se podstiče nagrađivanjem uspeha (teorija potkrepljenja neobihevioriste Hala). Asocijativna teorija učenja, odnosno teorija konekcionizma objašnjava misaone procese kao vezu između stimulusa i reakcije. Učenje je proces uspostavljanja beskrajno mnogo veza između stimulusa (draži) i reakcije (odgovora) subjekta na te draži. Prema Galjperinovoj teoriji etapnog formiranja umnih radnji osnovu saznajnih procesa i njihovih produkata (predstava i pojmova) čine umne radnje koje su zapravo interiorizirane spoljašnje radnje, a učenje je 
proces upravljanja misaonom aktivnošću. Kibernetička teorija (teorija sistema, informacija i komunikacija, upravljanja i regulisanja, algoritama, igara i drugo) takođe se posmatra kao jedna od osnova učenja pomoću kompjutera (Bogičević 2009: 473). Na ovu biheviorističku bazu nadovezuje se i instruktivizam uz primenu digitalnih medija.

Izlaganja mogu da se postave na internet, ali tradicionalno predavanje kao neefikasna nastavna forma time ne postaje ništa atraktivnije, jer umreženi nastavni materijali zastarevaju isto kao i neumreženi. Nove tehnologije daju mogućnost da se materijal upakuje na novi način, ali isto tako daju mogućnost za novu cenzuru, da se razmisli o pitanjima teorije nastave i o metodičko-didaktičkim pitanjima kao, na primer, o dijaloškim i kooperativnim formama učenja, o učeničkoj autonomiji i individualnim stilovima učenja i da se podstakne na empirijsko istraživanje o radu učenika s novim medijima (Tenberg 2003: 212). Informaciono-komunikaciona tehnologija može da doprinese inovativnim, drugačijim odnosima u pedagoškim aktivnostima (Loveless 2011: 311). Pedagogija koja prepoznaje kompleksan odnos između konteksta, alata za učenje i poučavanja, i sadržaja neće biti ni statična ni nameštena (Loveless 2011: 312), što na kraju uvek zavisi od nastavnika.

Nastava može da se oblikuje interaktivno uz pomoć interneta, pri čemu novi mediji daju mogućnost da se nastavni proces individualizuje i uskladi sa individualnim potrebama učenika, da se učenicima dozvoli veća mera autonomije i kontrole nad parametrima kao što su vreme, mesto i način učenja. Pojam interakcije se sada proširuje na eksternu i internu komunikativnu interakciju, uključuje ne samo komunikaciju sa nastavnicima i drugim polaznicima, već i aktivno bavljenje učenika materijalom za učenje bez obzira na medij u kojem je taj materijal prezentovan (Tenberg 2003: 210-211). Povezanost i interaktivnost su omogućeni i digitalnim društvnim mrežama, pri čemu članovi uzajamno podržavaju i održavaju, preuzimaju i proširuju ishode učenja (Davidson, Goldberg 2012: 256). Tako se i univerzitetski nastavnici povezuju sa studentima preko društvenih mreža i raznih platformi za učenje (Moodle, Google Classroom i dr.), materijali su dostupni u elektronskoj formi, diskusije se mogu voditi sinhrono i asinhrono, pitanja postavljati onlajn i oflajn itd. Mogućnosti komunikacije i saradnje se stalno proširuju, obogaćuju, postaju raznovrsnije, ali u svrhu konstrukcije znanja i interakcije se pre svega koriste interaktivne vežbe i zadaci.

\section{INTERAKTIVNE VEŽBE I ZADACI}

Interaktivne vežbe i zadatke uglavnom pripremaju nastavnici kod kuće, a mogu i studenti dobiti zadatak da ih sami sastavljaju jedni za druge. Jednostavni su 
za izradu i realizaciju, ne oduzimaju mnogo vremena, a mogu da budu od velike koristi u nastavi predavanja ukoliko nastavnik želi da izađe iz čistog verbalizma, bilo monološkog, bilo dijaloškog.

Interaktivne vežbe i zadaci mogu da se koriste $u$ različitim fazama predavanja, kao i s različitim ciljevima. Na početku časa mogu da služe za ponavljanje gradiva s prethodnog časa, u okviru glavnog dela i na kraju časa mogu doprineti utvrđivanju, produbljivanju i proveri prezentovanog znanja. Mogu da budu usmereni samo na kognitivne ciljeve znanja (pamćenja) i razumevanja (shvatanja), ali da obuhvate i primenu, analizu, sintezu (kreaciju) i evaluaciju (vrednovanje). Zadaci za niže kognitivne sposobnosti zahtevaju manje vremena i truda od zadataka za više kognitivne operacije za koje treba izdvojiti više vremena na času ili ih treba formulisati kao domaće zadatke. Nastavnik studentima može (d)ostaviti link na nekoj od platformi za učenje kao što su Mudl (Moodle) ili Gugl klasrum (Google Classroom), preko društvenih mreža, svog bloga, oblaka (na primer, Google Drive, OneDrive i dr.), u zavisnosti od dogovora, ličnih preferenci i drugih faktora - mogućnosti su brojne.

Za aktiviranje kognitivnih sposobnosti znanja (pamćenja) i razumevanja (shvatanja) pre svega su pogodne interaktivne vežbe koje se mogu kreirati u brojnim alatima (na primer, Learning Apps, Educaplay, Quizlet, Kahoot i mnoge druge). Studenti samostalno, u tandemu ili u grupi rešavaju zadatke (povezivanja, uređivanja, dopunjavanja i sl.) koristeći pametne telefone na času ili tablete i računare kod kuće. Ukoliko neki studenti nemaju pametni telefon s pristupom internetom, mogu da rade u paru ili grupi, što je dobar povod i prilika za kooperativno učenje. Tempo rada je različit za svakog pojedinca, tandem ili grupu, vežbe su dostupne i nakon časa i studenti ih mogu raditi kada i gde žele, koliko god im je puta potrebno da bi utvrdili i proverili svoje znanje i ponovili ga pred ispit. Iako je nastavnik uglavnom kreator vežbi, studenti im direktno pristupaju i rešavaju ih bez posredstva i uticaja nastavnika.

Za složenije zadatke pogodni su kvizovi i elektronski testovi. Nastavnik ih može kreirati na platformi za učenje Mudl (Moodle), na različitim internetstranicama kao što su Testmoz ili Gugl forms (Google Forms). Kvizovi se, takođe, mogu kreirati u brojnim alatima (Learning Apps i Kahoot). Bitno je da nastavnik prilikom formulacije kviza ili testa ne postavlja samo zadatke rekognicije, već i reprodukcije, odnosno i zadatke dopunjavanja, pri čemu treba posebno voditi računa o ključu, kako bi obuhvatio što više varijanti tačnih odgovora. Ukoliko su zadaci pravilno formulisani, mogu se aktivirati i sposobnosti analize, sinteze i primene. Kvizovi i testovi su dobar način provere znanja, naročito zato što i studenti i nastavnik odmah dobijaju povratnu informaciju, ne troši se dodatno 
vreme na korigovanje, a studenti ne moraju da čekaju rezultate. Preporučljivo je koristiti ih na početku časa kao ponavljanje, na kraju i posle časa kao utvrđivanje i proveru. Poželjno je da budu dostupni pre ispita, kako bi studenti mogli preko njih da ponove gradivo i provere stepen svog znanja i razumevanja.

$\mathrm{Za}$ aktiviranje kognitivnih sposobnosti analize i sinteze (kreacije) znanja pogodni su razni dijagrami koje mogu koristiti i nastavnici prilikom izlaganja, a i studenti prilikom utvrđivanja gradiva, na primer, na kraju časa. Traže dodatni angažman, te za njih treba izdvojiti više vremena, nekada čak i ceo čas. Ukoliko se rade preko digitalnih medija, potrebno je da studenti imaju pristup računaru. Ukoliko to nije moguće, odlična zamena je flipčart koji unosi i raznolikost u nastavu i omogućava veći stepen interaktivnosti. Studenti rade u grupi, komunikacija, saradnja i zajedničko učenje su na visokom nivou, realizuje se kooperativno-interaktivni model nastave uz uključivanje više čula i kreativnosti (vizuelni elementi).

U nastavi su veoma omiljene mape uma (mind-map) koje mogu da se kreiraju na flipčartu, u okviru Majkrosoft Ofis (Microsoft Office) paketa, kao i uz pomoć alata na internetu (na primer, Lucidchart ili Free Mind Map Software). Pogodne su za prikaz segmenata nekog pojma, ali iako nisu previše zahtevne, moraju se pratiti određena pravila u njenoj izradi (preglednost i sistematičnost). Tokom samog procesa potrebno je analizirati strukturu nekog pojma, napraviti selekciju bitnih segmenata (vrednovanje), odrediti njihov odnos i kreirati sliku uma na odgovarajući način.

Organigram (organizational chart) koristi se za prikaz strukture, odnosa među njenim segmentima i hijerarhije. Može se kreirati na flipčartu, uz pomoć SmartArt grafik (SmartArt graphic) u okviru Majkrosoft ofis paketa, a na internetu se mogu praviti i složeniji organigrami (u programima kao što su, na primer, Lucidchart, Smartdraw ili Canva). Pomoću organigrama može se prikazati neki složeni koncept, pri čemu studenti sami rekonstruišu odnos segmenata unutar tog koncepta (nadređeni - podređeni pojam, deo - celina) na osnovu prezentovanog gradiva.

Vremenska linija (timeline) predstavlja mogućnost za hronološki prikaz neke teme u prostornim odnosima - događaji koji su vremenski bliski prikazuju se kao prostorno blizu, a oni koji su vremenski udaljeni, prostorno se takođe smeštaju na većoj udaljenosti. Vremenska linija se može formulisati kao vežba u alatu Lerning Aps (Learning Apps), kao i da se kreira na internet-stranicama (na primer, Visme ili Timegraphics). Pogodna je za rekonstruisanje istorijskog aspekta neke teme, razvoja neke oblasti i slično. 
Dijagram toka (flowchart) služi za prikazivanje algoritma, toka rada ili procesa i može se takođe praviti u okviru Majkrosoft ofis paketa i s onlajn alatima (na primer, Lucidchart, Smartdraw, draw.io ili $A S Q$ ). Intelektualno je zahtevna jer je potrebno razmišljanje o (ne)mogućim i (ne)realnim alternativama, odnosno uslovima, uzrocima i posledicama (ako-onda). Iako se koristi u programiranju, može da se primeni za prikazivanje različitih procesa koji imaju više ishoda $u$ zavisnosti od potencijalno aktiviranih uslova.

U radu sa svim navedenim alatima bi trebalo da dođe do izražaja samostalnost i kreativnost studenata, njihova sposobnost konstrukcije znanja u interakciji s drugim studentima u grupnom radu, kao i u interakciji s nastavnim sredstvima i nastavnom građom. Nastava se obogaćuje, unosi se raznolikost, nastavnik se rasterećuje jer se aktivnost prebacuje na studente koji se aktiviraju i izvlače iz uloge pasivnih primalaca informacija. Ključno je da su zadaci adekvatno formulisani po releventnosti i po težini, odnosno da je njihova realizacija moguća.

\section{ZAKLJUČAK}

Predavanja su obavezan oblik univerzitetske nastave, iako je njihov status donekle diskutabilan, budući da se tradicionalni koncept predavanja - koji je još uvek zastupljen na mnogim univerzitetima - suštinski kosi sa zahtevima savremene nastave i njenim didaktičko-metodičkim principima. Savremena nastava bi trebalo da stavi težište na aktivnost studenata, na njihovu samostalnu kreaciju znanja i interakciju s drugim studentima, ali i nastavnim materijalima. Tradicionalni modeli predavanja zasnovani su na obradi i prezentaciji znanja, izrazitom verbalizmu (eventualno uz primenu demonstrativne metode) i frontalnom radu i ne mogu da ispune sve zahteve savremene nastave. Budući da su i dalje neophodna prilikom prezentacije znanja, naročito kod složenih tema i oblasti koje se obrađuju na univerzitetima, tradicionalna predavanja zasnovana na instruktivizmu ne treba ukinuti, ali ih treba dopuniti aktivnostima koje omogućavaju i konstrukciju znanja. Ako se predavanja obogate dijaloškom metodom (diskusija i postavljanje pitanja), nastava može da bude aktivnija i interaktivnija, naročito ukoliko pitanja postavljaju i studenti. Isto tako, interaktivnost i konstrukcija znanja se podstiču primenom kooperativnih oblika rada i digitalnih medija.

Budući da su današnji učenici rođeni u digitalno doba i da će oni vrlo brzo doći i na fakultete, digitalni mediji moraju da postanu deo savremene nastave kako ona ne bi ,ispala” iz svog vremena. Prilikom njihove implementacije presudno je da se koriste na adekvatan način radi ostvarivanja interaktivnosti i samostalne kreacije znanja. Nastavnici u tu svrhu treba da usvajaju i razvijaju digitalne 
kompetencije i da svoje didaktičko-metodičke kompetencije obogaćuju i prilagođavaju zahtevima digitalnog doba kako bi na odgovarajući način primenili digitalne medije u svrhu realizacije aktivne nastave $\mathrm{i}$ ostvarivanja svih nivoa kognitivnih ciljeva.

\section{LITERATURA}

Apel, H. J. (2003). Predavanje. Zagreb: Erudita.

Badstübner-Kizik, C. (2010). "Instruktivismus/ Instruktion", in Metzler Lexikon Fremdsprachendidaktik, hrsg. v. C. Surkamp (Stuttgart: Metzler): 115116.

Blei, D. (2003). "Aufgaben in einer konstruktivistischen Lernkultur". Deutsch als Fremdsprache: Zeitschrift zur Theorie und Praxis des Deutschunterrichts für Ausländer 40/4: 220-227.

Bogičević, D. (2009). „Interaktivna nastava kao inovativni model univerzitetskog predavanja". Inovacije u nastavi 22/2: 42-52.

Čakarević, D. (2014). „Koncept učenja u digitalnom dobu”. Zbornik radova Učiteljskog fakulteta 8: 207-214.

Davidson, C. N., \& Goldberg, D. Th. (2012). "Our Digital Age: Implications for Learning and its (Online) Institutions". E-Learning and Digital Media 9/3: 249-266.

Đorđević, V. (2007). „Inovativni modeli nastave (Integrativna nastava, Projektna nastava i Interaktivna nastava)". Obrazovna tehnologija 4: 76-96.

Ende, K., Grotjahn, R., Kleppin, K., \& Mohr, I. (2013). Curriculare Vorgaben und Unterrichtsplanung. München: Goethe-Institut -Klett-Langenscheidt.

Fadel, Ch., Bialik, M., \& Trilling, B. (2015). Four-dimensional Education: The Competences Learners Need to Succeed. Boston: Center for Curriculum Redesign.

Funke, H., Kuhn, Ch., Skiba, D., Spaniel-Weise, D., \& Wicke, R. E. (2014). Aufgaben, Übungen, Interaktion. München: Klett-Langenscheidt.

Ivić, I., Pešikan, A., \& Antić, S. (2001). Aktivno učenje. Beograd: Institut za psihologiju.

Loveless, A. (2011). "Technology, Pedagogy and Education: Reflections on the Accomplishment of What Teachers Know, Do and Believe in a Digital Age". Technology, Pedagogy and Education 20/3: 301-316.

Okvir digitalnih kompetencija: Nastavnik za digitalno doba (2017). Beograd: Ministarstvo prosvete, nauke i tehnološkog razvoja. 
Petrovački, Lj, \& Štasni, G. (2010). Metodički sistemi u nastavi srpskog jezika $i$ književnosti. Novi Sad: Filozofski fakultet.

Požar, H. (2017). „Organizacija uspešnog obrazovanja - između tradicionalne i nove nastave". Zbornik radova Filozofskog fakulteta 47/ 2: 337-353.

Raičević, V. (2011). Rečnik lingvodidaktičke terminologije. Beograd: Zavod za udžbenike.

Standardi za akreditaciju studijskih programa prvog i drugog nivoa visokog obrazovanja. Službeni glasnik 88: 162-170.

Tenberg, R. (2003). "Interaktionsformen und Neue Medien aus der Sicht des Fernlernens". Deutsch als Fremdsprache: Zeitschrift zur Theorie und Praxis des Deutschunterrichts für Ausländer 40/4: 210-219.

Terhart, E. (2009). Didaktik: Eine Einführung. Stuttgart: Reclam.

Vilotijević, M, \& Vilotijević, N. (2016). „Interaktivna nastava u maloj grupi”, u Modeli razvijajuće nastave (Beograd: Učiteljski fakultet Univerziteta u Beogradu): 111-118.

Nikolina Zobenica

University of Novi Sad

Faculty of Philosophy

Department for German Studies

\title{
KNOWLEDGE CONSTRUCTION AND INTERACTION AT UNIVERSITY LECTURES OF DIGITAL AGE
}

\begin{abstract}
Summary
Lectures are an obligatory part of university education in Serbia and it is even proscribed that they have to amount to 50 to $60 \%$ of all teaching classes in comparison to seminars and exercises. This gives an impression that lectures have been ascribed great relevance, although they have already been considered an outdated and inefficient teaching form for long time, because their purpose is only knowledge transfer without the activation of higher cognitive skills in students. Criticism of instructivism in university teaching has been mostly directed by representatives of constructivism and communicative didactics, consequently providing an incentive for a revision of this teaching form, as well as for the application of digital media for the purpose of innovation and modernization of university lectures. Taking into consideration the features of lectures, their predominant method (verbalism) and social form (frontal), the criticism is based on the lack of interaction and opportunities for autonomous knowledge construction. For the purpose of amending weaknesses of university lectures, teachers should also include discussions and encourage students to pose questions by themselves. It is also recommendable to implement digital media which provide learners with opportunities for autonomous construction of knowledge and interaction with other students and teaching materials, so that the higher cognitive skills such as analysis, synthesis, evaluation and creation can be activated. In the process of preparation, arrangement and management of digital teaching material, teachers
\end{abstract}


should demonstrate digital competences and adequate updated didactic competences for the education of the digital age in which students of today and tomorrow have been and will be born into. The task of teachers is and will be to show their students how to use digital media, not only for fun and games, but for learning as well.

Key words: constructivism, digital media, instructivism, interaction, lectures, university teaching.

Primljeno: 28. 5. 2019.

Prihvaćeno: 3. 7. 2019. 